\title{
Indications for and pregnancy outcomes of cervical cerclage: 11-year comparison of patients undergoing history-indicated, ultrasound- indicated, or rescue cerclage
}

\author{
Lucia LK Chan *, TW Leung, TK Lo, WL Lau, WC Leung
}

\section{A B S T R A C T}

Objectives: To review and compare pregnancy outcomes of patients undergoing history-indicated, ultrasound-indicated, or rescue cerclage.

Design: Case series with internal comparison.

Setting: A regional obstetric unit in Hong Kong.

Patients: Women undergoing cervical cerclage at Kwong Wah Hospital between 1 January 2001 and 31 December 2011.

Interventions: Cervical cerclage.

Main outcome measures: Pregnancy outcomes including miscarriage, gestational age at delivery, birth weight, and duration of pregnancy prolongation.

Results: Overall, 47 patients were included. Nine (19.1\%) pregnancies resulted in miscarriage. The median gestational age at delivery was 35.7 weeks. Among the 23 patients who had history-indicated cerclage, only four (17.4\%) had three or more previous second-trimester miscarriages or preterm deliveries. Among the 15 patients who had ultrasound-indicated cerclage, preoperative cervical length of $\leq 1.5 \mathrm{~cm}$ was associated with shorter prolongation of pregnancy, compared with that of $>1.5 \mathrm{~cm}$ (median, 12.1 vs 18.4 weeks; $\mathrm{P}=0.009)$. Among the nine women who had rescue cerclage, those who underwent the procedure before 20 weeks of gestation delivered earlier than those underwent cerclage later (median, 22.5 vs 34.1 weeks; $\mathrm{P}=0.048$ ).

Conclusions: Patients eligible for the Royal College of Obstetricians and Gynaecologists-recommended history-indicated cerclage remain few. The majority of patients may benefit from serial ultrasound monitoring of cervical length with or without ultrasound-indicated cerclage.

\section{Hong Kong Med J 2015;21:310-7}

DOI: 10.12809/hkmj144393

\author{
${ }^{1}$ LLK Chan *, MB, BS, MRCOG \\ ${ }^{1}$ TW Leung, PhD, FRCOG \\ ${ }^{2}$ TK Lo, MB, BS, FHKAM (Obstetrics and Gynaecology) \\ ${ }^{1}$ WL Lau, MB, BS, FRCOG \\ WC Leung, MD, FRCOG
}

\section{Department of Obstetrics and Gynaecology, Kwong Wah Hospital, Yaumatei, Hong Kong \\ 2 Department of Obstetrics and Gynaecology, Queen Mary Hospital, Pokfulam, Hong Kong}

* Corresponding author: lucia118@gmail.com

New knowledge added by this study

- Women who had rescue cerclage before 20 weeks of gestation delivered significantly earlier than those who had the procedure performed later, supporting the expert opinion in the Royal College of Obstetricians and Gynaecologists (RCOG) guideline.

Implications for clinical practice or policy

- The majority of patients may benefit from serial ultrasound monitoring of cervical length with or without ultrasound-indicated cerclage. A proposed algorithm on the management of patients, taking into consideration the RCOG guideline, is presented.

\section{Introduction}

Cervical cerclage was introduced by Shirodkar ${ }^{1}$ and McDonald ${ }^{2}$ in the 1950s, and has since become a common obstetric practice for the secondary prevention of preterm birth.,4 Cervical cerclage is performed in patients with a history of cervical insufficiency; preterm labour or second-trimester miscarriage; cervical dilatation in the second trimester; or shortened cervix noted on transvaginal ultrasound examination.

Although cervical cerclage is a common obstetric procedure, there is still controversy regarding its efficacy and patient selection. While some studies showed that cervical cerclage did not prolong gestation or improve neonatal survival, ${ }^{5-9}$ others suggested that the procedure was beneficial. ${ }^{10-15}$ 
For instance, a large trial demonstrated that the incidence of preterm delivery before 33 weeks was halved by cervical cerclage among women with a history of three or more preterm deliveries before 37 weeks. ${ }^{10}$ It was shown in a meta-analysis ${ }^{11}$ and another study ${ }^{12}$ that among women with shortened cervical length with or without prior preterm birth, the risk of preterm birth with or without perinatal mortality was significantly reduced by cerclage. Rescue cerclage was also found to prolong pregnancy, reduce the risk of preterm labour, ${ }^{13,14}$ and improve neonatal survival and birth weight, even in women considered at low risk of preterm delivery in view of their obstetric history. ${ }^{15}$

Decisions for cervical cerclage are difficult and are often based on the clinical judgement of the senior obstetrician. The guideline on cervical cerclage published by the Royal College of Obstetricians and Gynaecologists (RCOG) in 2011, which classifies cervical cerclage into history-indicated, ultrasoundindicated and rescue cerclage, provides updated evidence in this area. ${ }^{16}$

Nevertheless, on review of the literature worldwide, no studies have been reported to investigate systematically the use and outcomes of cervical cerclage according to this new RCOG classification. Hence, this study aimed to review the indications and the pregnancy outcomes (miscarriage, gestational age at delivery, birth weight, prolongation of pregnancy, and rate of preterm birth before 34 weeks) of cervical cerclage in a regional obstetric unit in Hong Kong according to the RCOG categorisation. Any change in practice of cervical cerclage in the unit over 11 years was also reviewed.

\section{Methods}

This was a retrospective review of patients who had cervical cerclage performed in a regional obstetric unit in Hong Kong between 1 January 2001 and 31 December 2011. Ethics approval from the local institutional review board (Kowloon West Cluster Clinical Research Ethics Committee Reference: KW/ EX-13-041[61-62]) was obtained. Patients who had undergone cervical cerclage were identified by the Clinical Data Analysis and Reporting System, which is a computerised database of the Hospital Authority, Hong Kong, using the key word "cervical cerclage". The clinical data for these patients were retrieved and reviewed.

The patients were divided into three subgroups for data analysis. Group 1 included patients with history-indicated cerclage, that is, cerclage was performed in women with obstetric or gynaecological risk factors for spontaneous secondtrimester loss or preterm delivery. Group 2 were patients with ultrasound-indicated cerclage, that is, cerclage was performed for women with cervical shortening $(<2.5 \mathrm{~cm})$ detected by transvaginal

\section{宮頸環扎術的適應症和治療結果：因病史、 超聲檢結果或急症情況進行環扎術的11年 病例比較}

\author{
陳露加、梁展華、盧子健、劉偉霖、梁永昌
}

目的：回顧並比較因病史、超聲檢結果或急症情況進行宮頸環扎術的 病例。

設計：病例系列與內部比較。

安排：香港一所分區醫院的產科部門。

患者：2001年1月 1 日至 2011 年 12 月 31 日期間在廣華醫院進行宮頸環 扎術的病人。

干預：宮頸環扎術。

主要結果測量：流產率、分婏時胎齡、胎兒出生體重和延長孕週時間 等娃娠結果。

結果：47個病例中有9例 $(19.1 \%)$ 流產。分婏時的胎齡中位數為第 35.7 週。因早產病史須進行宮頸環扎術的23例中, 只有4例 ( $17.4 \%)$ 有三次或以上中期流產或早產史。因超聲檢結果顯示宮頸機能不全須 進行環扎術的 15 例中, 與術前宮頸長度 $>1.5$ 厘米的組別相比, 宮頸 長度 $\leq 1.5$ 厘米的組別與延長孕週週數較短有關（中位數：18.4比 12.1 週 ; P=0.009）。因急症情況須施行環扎術的9例中, 與孕齡 20 週後 才進行環扎術的病例比較, 在孕齡 20 週前已進行手術的病例分娩時間 較早 (中位數34.1週比22.5週； $\mathrm{P}=0.048$ )

結論：本研究發現符合英國皇家婦產科學院的指南建議因病史須進行 宮頸環扎術的病例屬少數。對於懷疑宮頸機能不全的孕婦, 進行連串 超聲檢以監測宮頸長度對於大多數病例有利。

ultrasound examination, without exposure of fetal membranes in the vagina. This group comprised women who planned for history-indicated cerclage with preoperative sonographic finding of shortened cervix; had a history of preterm delivery before 37 weeks or second-trimester miscarriage(s) and underwent ultrasound monitoring of cervical length; or were incidentally found to have sonographic cervical shortening. Regular ultrasound examination was not performed for all patients and, if done, the frequency of monitoring was determined individually. Group 3 consisted of patients undergoing rescue cerclage, that is, cerclage was performed for women with premature cervical dilatation and exposure of fetal membranes in the vagina, which was either detected by ultrasound examination of the cervix or by speculum/physical examination for symptoms such as vaginal discharge, bleeding, or 'sensation of pressure, with or without a history of preterm birth before 37 weeks or second-trimester losses.

The definitions of history-indicated cerclage and ultrasound-indicated cerclage in this study were not exactly the same as the RCOG definitions, ${ }^{16}$ which suggest that history-indicated cerclage should 
be offered to women with three or more previous preterm births and/or second-trimester losses, while ultrasound-indicated cerclage should be offered to women with one or more previous preterm birth or second-trimester loss and sonographic cervical shortening $(\leq 2.5 \mathrm{~cm})$ before 24 weeks of gestation. To explore the significance of the differences in the category definitions, a sub-analysis was performed by dividing the present cohort into two groups. Group A included women who underwent historyindicated or ultrasound-indicated cerclage as defined by the RCOG guideline. Group B included women who had the procedure performed without strictly following the RCOG guideline.

All cervical cerclage procedures were performed by a senior obstetrician using the McDonald's technique with Mersilene tape (Ethicon, West Somerville [NJ], US). Perioperative management-such as the use of prophylactic antibiotics and/or tocolytics, bed rest, and the choice of anaesthesia-was at the discretion of the operating team. The interval between the diagnosis of cervical incompetence and the performance of rescue cervical cerclage ranged from 0 to 3 days.

The Statistical Package for the Social Sciences (Windows version 20.0; SPSS Inc, Chicago [IL], US) was used for statistical analysis. The pregnancy outcomes studied included miscarriage, gestational age at delivery, birth weight, and duration of prolongation of pregnancy. Kruskal-Wallis test and Pearson Chi squared test were employed to analyse the relationship between indication for cerclage and various pregnancy outcomes. Patients who had history-indicated or ultrasound-indicated cerclage as defined by the RCOG guideline (group A) were compared with patients who had the procedure performed without strictly following the RCOG definition (group B) by the Mann-Whitney $U$ test and Fisher's exact test. Fisher's exact test and Mann-Whitney $U$ test were used, respectively, to compare the indications for cerclage and the various pregnancy outcomes between two different time periods (2001-2005 vs 2006-2011). A P value of less than 0.05 was taken as statistically significant.

\section{Results}

Overall, 47 patients with a singleton pregnancy were included in this study. The majority $(87.2 \%)$ were Chinese. No immediate operative complications associated with cervical cerclage (namely membrane rupture or miscarriage within 1 week) occurred except for one miscarriage.

Among the 47 patients, nine (19.1\%) pregnancies resulted in miscarriage, and 28 (59.6\%) patients delivered after 34 weeks of gestation. The median gestational age at delivery was 35.7 (range, 14.9-40.1) weeks, with a median birth weight of 2270 (range, 75-3960) g. The median prolongation of pregnancy after cervical cerclage was 17.3 (range, 0.3-27.1) weeks. Among the 38 patients who delivered after 24 weeks of gestation, 29 (76.3\%) delivered by normal spontaneous delivery, eight (21.1\%) by lower segment caesarean section, and one $(2.6 \%)$ by vacuum extraction.

\section{Patients undergoing history-indicated cerclage (group $1 ; n=23$ )}

Cerclage was performed at a median gestation of 14.6 (range, 12.4-19.6) weeks (Table 1). The median cervical length of the 20 patients who had it measured preoperatively by ultrasound examination was 3.5 (range, 2.5-4.8) cm. Four (17.4\%) patients had three or more previous second-trimester miscarriages or preterm deliveries (ie the true history-indicated cerclage group as defined by the RCOG guidelines) and $13(56.5 \%)$ had two or more second-trimester miscarriages or preterm deliveries. One patient did not have previous second-trimester miscarriage or preterm delivery, but had a history of large loop excision of transformation zone for cervical intraepithelial neoplasia, two terminations of pregnancy, and recurrent first-trimester miscarriages.

No significant association was found between pregnancy outcomes and the gestation at which cerclage was performed. The pregnancy outcomes of the four women with three or more previous second-trimester miscarriages or preterm deliveries were compared with the other 19 women who had less than three second-trimester miscarriages or preterm deliveries. The former group tended to have a better pregnancy outcome, with higher gestational age at delivery (median, 38.1 weeks vs 37.4 weeks) and heavier birth weight (median, 3135 vs $2570 \mathrm{~g}$ ) than the latter group, although these differences did not reach statistical significance.

\section{Patients undergoing ultrasound-indicated cerclage (group 2; $\mathbf{n = 1 5}$ )}

Cerclage was performed at a median gestation of 18.6 (range, 14.3-23.4) weeks (Table 1). Shortened cervical length with or without funnelling of the cervix was detected on ultrasound examination. The median cervical length was 1.5 (range, 0-2.4) cm. All patients had cervical length of $<2.5 \mathrm{~cm}$.

Patients with a preoperative cervical length of $\leq 1.5 \mathrm{~cm}$ had significantly shorter prolongation of pregnancy compared with patients with a preoperative cervical length of $>1.5 \mathrm{~cm}$ (median, 12.1 vs 18.4 weeks, $\mathrm{P}=0.009)$. Seven $(46.7 \%)$ patients had cervical funnelling. No significant difference in pregnancy outcomes was detected between patients with and without cervical funnelling seen in the preoperative ultrasound examination. Among the 15 patients undergoing ultrasound-indicated cerclage, $13(86.7 \%)$ had a history of second- 
TABLE I. Demographic characteristics and pregnancy outcomes of patients with different indications for cervical cerclage

\begin{tabular}{|c|c|c|c|c|}
\hline & \multicolumn{3}{|c|}{ Median (range) or No. (\%) } & \multirow[t]{2}{*}{$P$ value } \\
\hline & $\begin{array}{l}\text { History-indicated } \\
\text { cerclage }(n=23)\end{array}$ & $\begin{array}{l}\text { Ultrasound-indicated } \\
\text { cerclage }(n=15)\end{array}$ & Rescue cerclage $(n=9)$ & \\
\hline Age (years) & $34(24-40)$ & $35(24-40)$ & $33(31-40)$ & $0.776^{\star}$ \\
\hline Body mass index $\left(\mathrm{kg} / \mathrm{m}^{2}\right)$ & $24.5(17.7-30.7)$ & $25.7(17.3-33.0)$ & $24.8(15.1-25.4)$ & $0.703^{*}$ \\
\hline Parity & & & & 0.893† \\
\hline Nulliparous & $9(39.1 \%)$ & $7(46.7 \%)$ & $4(44.4 \%)$ & \\
\hline Multiparous & $14(60.9 \%)$ & $8(53.3 \%)$ & $5(55.6 \%)$ & \\
\hline $\begin{array}{l}\text { History of preterm birth or second-trimester } \\
\text { miscarriage }\end{array}$ & $\begin{array}{cc}<3 & \geq 3 \\
19(82.6 \%) & 4(17.4 \%)\end{array}$ & $\begin{array}{cc}0 & \geq 1 \\
2(13.3 \%) & 13(86.7 \%)\end{array}$ & $\begin{array}{cc}0 & \geq 1 \\
3(33.3 \%) & 6(66.7 \%)\end{array}$ & - \\
\hline Gestation at cerclage (weeks) & $14.6(12.4-19.6)$ & $18.6(14.3-23.4)$ & $19.3(16.1-23.0)$ & $<0.001^{*}$ \\
\hline No. of patients with miscarriage & $2(8.7 \%)$ & 3 (20.0\%) & $4(44.4 \%)$ & $0.070 \dagger$ \\
\hline Gestational age at delivery (weeks) & $37.6(18.3-40.1)$ & $35.4(14.9-39.6)$ & $24.3(17.9-34.6)$ & $0.007^{\star}$ \\
\hline $\begin{array}{l}\text { No. of patients with preterm delivery before } \\
34 \text { weeks of gestation }\end{array}$ & $6(26.1 \%)$ & $6(40.0 \%)$ & 7 (77.8\%) & $0.028 \dagger$ \\
\hline Birth weight (g) & $2860(180-3960)$ & $2270(75-3210)$ & $695(120-2340)$ & $0.005^{\star}$ \\
\hline Prolongation of pregnancy (weeks) & $22.3(2.4-27.1)$ & $17.0(0.3-22.3)$ & $5.7(1.7-14.4)$ & $<0.001^{*}$ \\
\hline
\end{tabular}

* Kruskal-Wallis test

+ Pearson Chi squared test

trimester miscarriages or preterm deliveries. No significant difference in pregnancy outcomes was found between patients with or without a history of second-trimester miscarriages or preterm deliveries.

\section{Patients undergoing rescue cerclage (group $3 ; \mathbf{n}=9$ )}

Rescue cerclage was performed at a median gestation of 19.3 (range, 16.1-23.0) weeks (Table 1). Cervical dilatation ranged from 2 to $3 \mathrm{~cm}$ at the time of diagnosis. Among the nine patients undergoing rescue cerclage, six (66.7\%) had a history of secondtrimester miscarriages or preterm deliveries. The diagnosis of cervical dilatation among these six women was made by either ultrasound assessment or physical examination based on symptoms. One patient had history-indicated cervical cerclage performed at a private hospital at 12 weeks of gestation. She presented with increased vaginal discharge at 22 weeks and was found to have cervical dilatation with a loosened cerclage stitch. Rescue cerclage was performed.

All the patients who miscarried after rescue cerclage had the procedure performed before 20 weeks of gestation. Women who underwent cerclage before 20 weeks delivered at an earlier gestation (median, 22.5 vs 34.1 weeks; $\mathrm{P}=0.048$ ) and had smaller babies (median birth weight, 565 vs 2190 g; $\mathrm{P}=0.048$ ) than women who had cerclage at a later gestation.

\section{Comparison among the three groups of patients}

There were no significant differences in age, body mass index, or parity between the three groups. Cerclage was performed at a significantly earlier gestation for patients with history-indicated cerclage compared with the other two groups $(\mathrm{P}<0.001$; Table 1).

Regarding the pregnancy outcomes, it seems that patients undergoing rescue cerclage had a higher incidence of miscarriage than the other two groups (44.4\% vs $20.0 \%$ in the ultrasound-indicated group and $8.7 \%$ in the history-indicated group), although the differences did not reach statistical significance $(\mathrm{P}=0.07)$, probably because of the small number of patients included in each group (Table $1)$.

Patients in the history-indicated and ultrasound-indicated cerclage groups had significantly longer prolongation of pregnancy, delivered at later gestation, and had heavier birth weight babies than women in the rescue cerclage group (Table 1). Nevertheless, there were no statistically significant differences in the gestational age at delivery or birth weight between patients in history-indicated cerclage group and the ultrasoundindicated group, although the former group had significantly longer prolongation of pregnancy than the latter group $(\mathrm{P}=0.002)$. 
Comparison between patients in group $A$ and group $B$ according to the Royal College of Obstetricians and Gynaecologists definition

Comparison between patients who had historyindicated or ultrasound-indicated cerclage as defined by the RCOG guideline (group A) with patients who had the procedure performed without strictly following the RCOG definition (group B) was made. Group A consisted of four patients who had history-indicated cerclage and 13 patients who had ultrasound-indicated cerclage. Group B comprised 19 patients who had history-indicated cerclage and two patients who had ultrasound-indicated cerclage. No significant differences were detected in the demographic characteristics between the two groups. There were also no significant differences in the pregnancy outcomes between the two groups, including miscarriage rate, gestational age at delivery, preterm delivery rate before 34 weeks of gestation, birth weight, and prolongation of pregnancy (Table 2).

\section{Comparison of the cerclage practice between 2001-2005 and 2006-2011}

There was a trend for more ultrasound-indicated cerclage and rescue cerclage in 2006-2011 than in 2001-2005. More history-indicated or ultrasoundindicated cerclages were performed according to the RCOG's recommendation in 2006-2011 than in 2001-2005 (50\% vs 38.9\%), although the difference did not reach statistical significance $(\mathrm{P}=0.532)$, probably because of the small sample size (Table 3 ).

Pregnancy outcomes were similar between the two periods. However, there was less use of prophylactic tocolysis, but more frequent use of spinal anaesthesia and prophylactic antibiotics in
2006-2011 than in 2001-2005. The median duration of hospital stay was also significantly shorter in 2006-2011 than in 2001-2005 (Table 3).

\section{Discussion}

This retrospective study reviewed systematically the use and outcomes of cervical cerclage according to the new 2011 RCOG categorisation, ${ }^{16}$ although not all cases followed strictly the exact definition of history-indicated or ultrasound-indicated cerclage in the RCOG guideline. The data from the study may help provide more evidence on the application of the new guideline for making the decision for cervical cerclage among women at risk of or diagnosed with cervical incompetence.

In this study, only four (17.4\%) patients fulfilled the RCOG recommendation ${ }^{16}$ for historyindicated cerclage (ie $\geq 3$ previous second-trimester miscarriages or preterm deliveries), although more than half of the women in the group $(n=13,56.5 \%)$ had a history of two or more second-trimester miscarriages or preterm deliveries. This suggests that in clinical practice, women eligible for cerclage based on their obstetric history alone are few and, hence, serial ultrasound monitoring of cervical length is needed for most of the women at risk for cervical incompetence.

The optimal cervical length for recommending cerclage is controversial. ${ }^{22,17}$ One multicentre trial suggested that cerclage should be performed at cervical length of $<1.5 \mathrm{~cm},{ }^{12}$ whereas a meta-analysis suggested that cerclage should be done for women with a singleton gestation with a previous preterm birth and cervical length of $<2.5 \mathrm{~cm} .{ }^{17}$ Our study showed that patients with preoperative cervical length of $\leq 1.5 \mathrm{~cm}$ had shorter prolongation of

TABLE 2. Comparison between patients who had history-indicated or ultrasound-indicated cervical cerclage as defined by the RCOG guideline (group A) with patients who had the procedure performed without strictly following the RCOG definition (group B)

\begin{tabular}{|c|c|c|c|}
\hline & \multicolumn{2}{|c|}{ Median (range) or No. (\%) } & \multirow[t]{2}{*}{$P$ value } \\
\hline & Group $A^{*}(n=17)$ & Group B† $(n=21)$ & \\
\hline Age (years) & $32(24-40)$ & $35(26-40)$ & $0.121 \ddagger$ \\
\hline BMI $\left(\mathrm{kg} / \mathrm{m}^{2}\right)$ & $25.8(17.3-33.0)$ & $24.4(17.7-30.7)$ & $0.337 \ddagger$ \\
\hline No. of patients with miscarriage & $2 / 17(11.8 \%)$ & $3 / 18(16.7 \%)$ & $0.604 \S$ \\
\hline Gestational age of delivery (weeks) & $36.3(14.9-39.3)$ & $37.4(18.3-40.1)$ & $0.486 \ddagger$ \\
\hline No. of patients with preterm delivery before 34 weeks of gestation & $5 / 17(29.4 \%)$ & $7 / 21(33.3 \%)$ & $0.539 \S$ \\
\hline Birth weight $(g)$ & $2440(75-3430)$ & $2570(180-3960)$ & $0.794 \ddagger$ \\
\hline Prolongation of pregnancy (weeks) & $18.1(0.3-23.4)$ & $22.1(2.4-27.1)$ & $0.089 \ddagger$ \\
\hline
\end{tabular}

Abbreviations: $\mathrm{BMI}=$ body mass index; $\mathrm{RCOG}=$ Royal College of Obstetricians and Gynaecologists

* Group A: 4 patients with history-indicated cerclage and 13 patients with ultrasound-indicated cerclage

+ Group B: 19 patients with history-indicated cerclage and 2 patients with ultrasound-indicated cerclage

‡ Mann-Whitney $U$ test

$\S$ Fisher's exact test 
TABLE 3. Comparison of perioperative management, mode of anaesthesia, and pregnancy outcomes for women undergoing cervical cerclage performed between 200I-2005 and 2006-20II

\begin{tabular}{|c|c|c|c|}
\hline & \multicolumn{2}{|c|}{ No. (\%) or median (range) } & \multirow[t]{2}{*}{$P$ value } \\
\hline & 2001-2005 & 2006-2011 & \\
\hline No. of patients & 19 & 28 & - \\
\hline \multicolumn{4}{|l|}{ Indication for cerclage } \\
\hline History-indicated & $13(68.4 \%)$ & $10(35.7 \%)$ & $0.050 \ddagger$ \\
\hline US-indicated & $5(26.3 \%)$ & $10(35.7 \%)$ & \\
\hline Rescue & $1(5.3 \%)$ & $8(28.6 \%)$ & \\
\hline \multicolumn{4}{|l|}{ Group A or B } \\
\hline Group A* & 7 (38.9\%) & $10(50 \%)$ & $0.532 \ddagger$ \\
\hline Group B† & $11(61.1 \%)$ & $10(50 \%)$ & \\
\hline \multicolumn{4}{|l|}{ Tocolysis } \\
\hline Yes & $14(73.7 \%)$ & $6(21.4 \%)$ & $0.001 \ddagger$ \\
\hline No & $5(26.3 \%)$ & $22(78.6 \%)$ & \\
\hline \multicolumn{4}{|l|}{ Prophylactic antibiotics } \\
\hline Yes & $15(78.9 \%)$ & $28(100.0 \%)$ & $0.022 \ddagger$ \\
\hline No & $4(21.1 \%)$ & 0 & \\
\hline \multicolumn{4}{|l|}{ Mode of anaesthesia } \\
\hline General anaesthesia & $17(89.5 \%)$ & $11(39.3 \%)$ & $0.001 \neq$ \\
\hline Spinal anaesthesia & $2(10.5 \%)$ & $17(60.7 \%)$ & \\
\hline Duration of stay after cervical cerclage (days) & $5(1-65)$ & $2(1-54)$ & $0.005 \S$ \\
\hline No. of patients with miscarriage & $4(21.1 \%)$ & $5(17.9 \%)$ & $0.535 \ddagger$ \\
\hline Gestational age at delivery (weeks) & $35.9(14.9-40.1)$ & $35.6(17.9-39.6)$ & $0.704 \S$ \\
\hline Birth weight (g) & $2060(75-3960)$ & $2305(120-3420)$ & $0.897 \S$ \\
\hline Prolongation of pregnancy (weeks) & $18.4(0.3-25.4)$ & $16.7(1.7-27.1)$ & $0.558 \S$ \\
\hline \multicolumn{4}{|c|}{ Mode of delivery (excluding patients with miscarriage) } \\
\hline Normal vaginal delivery & $10(66.7 \%)$ & $19(82.6 \%)$ & $0.332 \ddagger$ \\
\hline Instrumental delivery & $1(6.7 \%)$ & 0 & \\
\hline Caesarean section & $4(26.7 \%)$ & $4(17.4 \%)$ & \\
\hline
\end{tabular}

Abbreviations: RCOG = Royal College of Obstetricians and Gynaecologists; US = ultrasound

* Group A: patients who had history-indicated or ultrasound-indicated cerclage as defined by the RCOG guideline

† Group B: patients who had the procedure performed without strictly following the RCOG definition

$\neq$ Fisher's exact test

$\S$ Mann-Whitney $U$ test

pregnancy compared with those with preoperative trimester miscarriages in the history-indicated cervical length of 1.5 to $2.4 \mathrm{~cm}$, supporting the cerclage group and patients with one or more recommendation that cervical cerclage should be previous preterm delivery or second-trimester offered if sonographic cervical shortening to $\leq 2.5$ miscarriage in the ultrasound-indicated cerclage $\mathrm{cm}$ is detected (Fig). No significant difference in group, and therefore was expected to carry a higher pregnancy outcomes was detected between patients risk for preterm delivery or miscarriage and, hence, with and without preoperative sonographic cervical a worse pregnancy outcome compared with group funnelling. Review of the literature also suggests that B patients, who did not strictly fulfil the RCOG cervical funnelling is not an independent risk factor recommendation. Interestingly, no significant for preterm birth. ${ }^{18}$ Hence, cervical funnelling is not difference in pregnancy outcomes was detected recommended as a criterion to offer cerclage.

between group A and group B patients. This may

Group A comprised patients who had three be due to the small sample size in each group. This, or more previous preterm deliveries or second- however, may mean that a less stringent criterion 


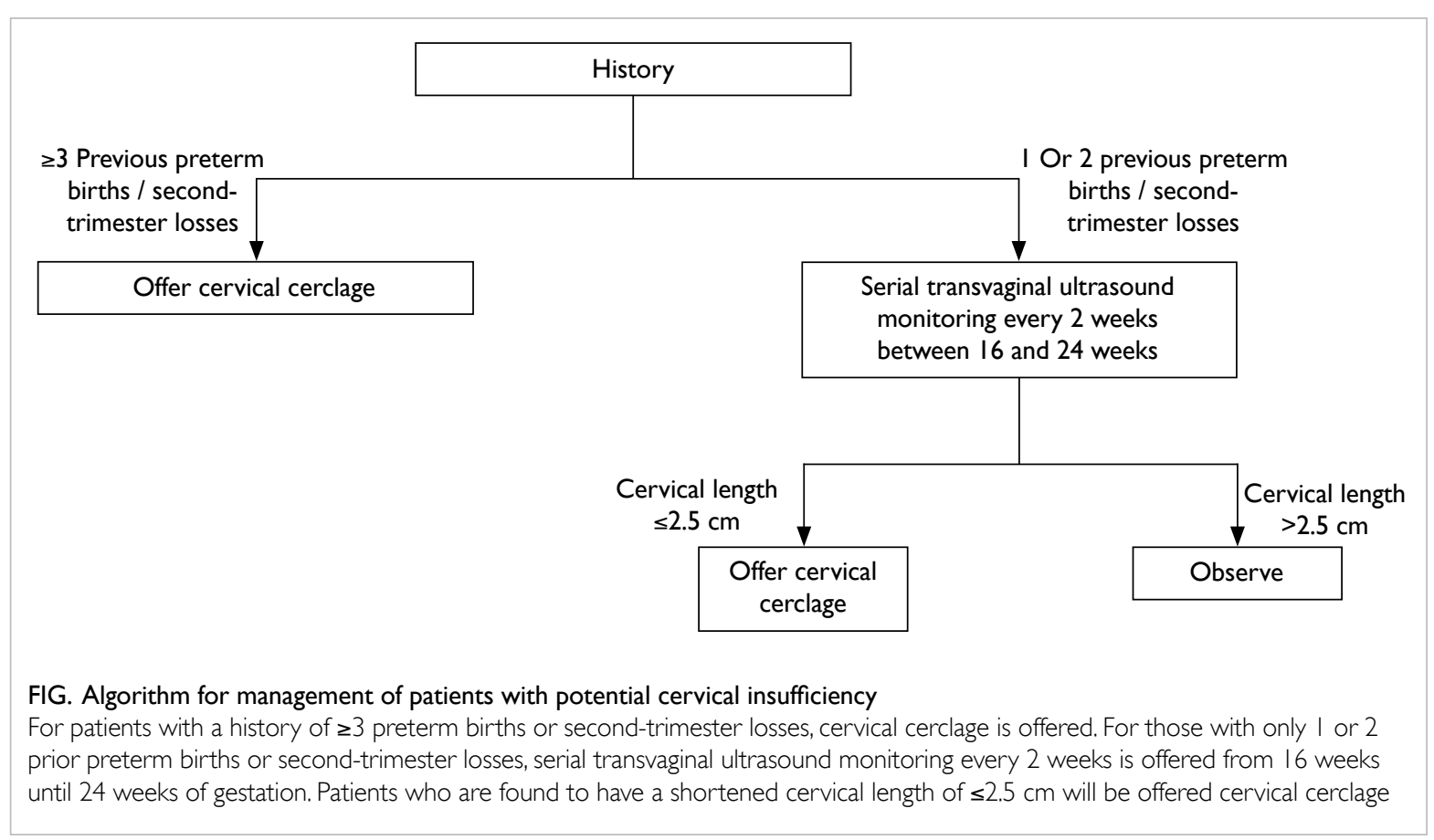

to offer cerclage other than the present RCOG recommendation may still be helpful for women at risk for cervical incompetence. A prospective study with a larger sample size to compare the pregnancy outcomes between these two groups of patients is warranted.

Women who had rescue cerclage before 20 weeks delivered significantly earlier than those who underwent the procedure later than 20 weeks. Although it is stated in the 2011 RCOG guideline that "in cases presenting before 20 weeks of gestation, insertion of a rescue cerclage is highly likely to result in a preterm delivery before 28 weeks of gestation", ${ }^{16}$ this is based on expert opinion only, rather than data from previous studies. The result from this study provides new evidence to support such expert opinion.

Among patients with history-indicated or ultrasound-indicated cerclage, more patients fulfilled the RCOG's recommendation in 2006-2011 than in $2001-2005$ (50.0\% vs $38.9 \%)$. This suggests that even before the publication of the RCOG guideline in 2011, the practice of cervical cerclage has already been changing, with a shift towards more stringent criteria for offering cerclage.

\section{Strengths and limitations of this study}

This study reviewed systematically the use and outcomes of cervical cerclage according to the categories in the new 2011 RCOG guideline. ${ }^{16}$ The data obtained may help in patient selection and counselling for cerclage. The major limitations include small sample size and lack of control groups. Moreover, not all patients included in the historyindicated and ultrasound-indicated groups fulfilled exactly the strict RCOG definitions for the respective groups.

\section{The way forward}

Although the RCOG guideline recommends historyindicated cerclage be performed in patients with a history of three or more previous second-trimester miscarriages or preterm deliveries, in clinical practice, this group of patients remains small. In the present study, only $17.4 \%$ of patients in the historyindicated cerclage group fulfilled such criteria. The majority of patients with potential cervical insufficiency encountered are those with a history of one or two previous second-trimester miscarriages or preterm deliveries, who may benefit from serial ultrasound monitoring of cervical length with or without ultrasound-indicated cerclage. Based on the findings from this study, an algorithm for the management of patients with potential cervical insufficiency is proposed (Fig).

A major limitation of ultrasound monitoring is the difficulty of timely identification of sudden cervical shortening and dilatation. The recommended frequency of ultrasound surveillance is not well established. Since this study demonstrated that rescue cerclage performed before 20 weeks of gestation was associated with a much poorer pregnancy outcome 
than procedures done at a later gestation, it is recommended that among patients with a history of one or two previous preterm births or secondtrimester miscarriages, serial ultrasound monitoring should be performed every 2 weeks between 16 and 24 weeks of gestation (Fig). This may help optimise the early detection of cervical shortening in time and, hence, allow ultrasound-indicated cerclage be performed instead of rescue cerclage. Nevertheless, such practice requires a greater demand on manpower to perform ultrasound examinations and may not be applicable in small units with few staff. In order to improve the quality of care for patients with potential cervical insufficiency, allocation of resources for serial ultrasound monitoring for this group of patients is warranted.

\section{Conclusions}

Patients eligible for history-indicated cerclage according to the RCOG recommendation remain few. The majority of patients may benefit from serial ultrasound monitoring of cervical length with or without ultrasound-indicated cerclage, which is preferably performed at a cervical length between 1.5 and $2.5 \mathrm{~cm}$.

\section{Declaration}

The authors have no conflicts of interest to declare.

\section{References}

1. Shirodkar VN. A new method of operative treatment for habitual abortion in the second trimester of pregnancy. Antiseptic 1955;52:299-300.

2. McDonald IA. Suture of the cervix for inevitable miscarriage. J Obstet Gynaecol Br Emp 1957;64:346-50.

3. Spong CY. Prediction and prevention of recurrent spontaneous preterm birth. Obstet Gynecol 2007;110:40515.

4. Flood K, Malone FD. Prevention of preterm birth. Semin Fetal Neonatal Med 2012;17:58-63.

5. Rush RW, Isaacs S, McPherson K, Jones L, Chalmers I, Grant A. A randomized controlled trial of cervical cerclage in women at high risk of spontaneous preterm delivery. $\mathrm{Br}$ J Obstet Gynaecol 1984;91:724-30.

6. Berghella V, Daly SF, Tolosa JE, et al. Prediction of preterm delivery with transvaginal ultrasonography of the cervix in patients with high-risk pregnancies: does cerclage prevent prematurity? Am J Obstet Gynecol 1999;181:809-15.

7. Rust OA, Atlas RO, Reed J, van Gaalen J, Balducci J. Revisiting the short cervix detected by transvaginal ultrasound in the second trimester: why cerclage therapy may not help. Am J Obstet Gynecol 2001;185:1098-105.

8. Berghella V, Odibo AO, Tolosa JE. Cerclage for prevention of preterm birth in women with a short cervix found on transvaginal ultrasound examination: a randomized trial. Am J Obstet Gynecol 2004;191:1311-7.

9. To MS, Alfirevic Z, Heath VC, et al. Cervical cerclage for prevention of preterm delivery in women with short cervix: randomised controlled trial. Lancet 2004;363:1849-53.

10. Final report of the Medical Research Council/Royal College of Obstetricians and Gynaecologists multicentre randomised trial of cervical cerclage. MRC/RCOG Working Party on Cervical Cerclage. Br J Obstet Gynaecol 1993;100:516-23.

11. Berghella V, Odibo AO, To MS, Rust OA, Althuisius SM. Cerclage for short cervix on ultrasonography: metaanalysis of trials using individual patient-level data. Obstet Gynecol 2005;106:181-9.

12. Owen J, Hankins G, Iams JD, et al. Multicenter randomized trial of cerclage for preterm birth prevention in high-risk women with shortened midtrimester cervical length. Am J Obstet Gynecol 2009;201:375.e1-8.

13. Olatunbosun OA, al-Nuaim L. Turnell RW. Emergency cerclage compared with bed rest for advanced cervical dilatation in pregnancy. Int Surg 1995;80:170-4.

14. Althuisius SM, Dekker GA, Hummel P, van Geijn HP; Cervical incompetence prevention randomized cerclage trial. Cervical incompetence prevention randomized cerclage trial: emergency cerclage with bed rest versus bed rest alone. Am J Obstet Gynecol 2003;189:907-10.

15. Daskalakis G, Papantoniou N, Mesogitis S, Antsaklis A. Management of cervical insufficiency and bulging fetal membranes. Obstet Gynecol 2006;107:221-6.

16. Cervical cerclage (Green-top Guideline No. 60), May 2011. London: Royal College of Obstetricians and Gynaecologists; 2011.

17. Berghella V, Keeler SM, To MS, Althuisius SM, Rust OA. Effectiveness of cerclage according to severity of cervical length shortening: a meta-analysis. Ultrasound Obstet Gynecol 2010;35:468-73.

18. To MS, Skentou C, Liao AW, Cacho A, Nicolaides KH. Cervical length and funneling at 23 weeks of gestation in the prediction of spontaneous early preterm delivery. Ultrasound Obstet Gynecol 2001;18:200-3. 